University of Nebraska - Lincoln

DigitalCommons@University of Nebraska - Lincoln

Faculty Publications from the Harold W. Manter Laboratory of Parasitology

1978

\title{
Suppressed Rejection of Trichinella spiralis in Immunized Rats Concurrently Infected with Eimeria nieschulzi
}

Donald W. Duszynski

University of New Mexico, eimeria@unm.edu

Deborah Russell

Shirley A. Roy

Gilbert A. Castro

University of Texas Medical Schoo

Follow this and additional works at: https://digitalcommons.unl.edu/parasitologyfacpubs

Part of the Parasitology Commons

Duszynski, Donald W.; Russell, Deborah; Roy, Shirley A.; and Castro, Gilbert A., "Suppressed Rejection of Trichinella spiralis in Immunized Rats Concurrently Infected with Eimeria nieschulzi" (1978). Faculty Publications from the Harold W. Manter Laboratory of Parasitology. 126.

https://digitalcommons.unl.edu/parasitologyfacpubs/126

This Article is brought to you for free and open access by the Parasitology, Harold W. Manter Laboratory of at DigitalCommons@University of Nebraska - Lincoln. It has been accepted for inclusion in Faculty Publications from the Harold W. Manter Laboratory of Parasitology by an authorized administrator of DigitalCommons@University of Nebraska - Lincoln. 


\title{
SUPPRESSED REJECTION OF TRICHINELLA SPIRALIS IN IMMUNIZED RATS CONCURRENTLY INFECTED WITH EIMERIA NIESCHULZI*
}

\author{
Donald W. Duszynski, $\dagger$ Deborah Russell, + Shirley A. Roy, + and Gilbert A. Castro: \\ Department of Physiology, University of Texas Medical School, Houston, Texas 77025
}

ABstract: This study deals with the effect of Eimeria nieschulzi infection on the host immune response to Trichinella spiralis. Six male Sprague-Dawley rats were inoculated with $10^{4}$ and six with $10^{\prime \prime}$ sporulated $E$. nieschulzi oocysts. On days 2,8 , and 16 postinoculation (PI), two rats from each infected group, and their paired uninfected controls, were killed and mucosal scrapings from their small intestines were assayed for peroxidase activity. Peroxidase levels were higher than corresponding control values on days 2 and 16 PI and significantly lower than the controls on day 8 PI. These data led us to initiate the present study because infection by $T$. spiralis in rats is known to cause an elevated gut peroxidase level which, in turn, is thought to contribute to worm expulsion. Twentyeight male rats were then immunized by administration of $7.5 \times 10^{3}$ freshly isolated T. spiralis larvae. Thirty-two days after immunization 16 rats were inoculated with $5 \times 10^{5}$ sporulated oocysts of $E$. nieschulzi. The other 12 rats were retained as immune controls. Each of the 28 rats was challenged with $7.5 \times 10^{3} \mathrm{~T}$. spiralis larvae between 2 and 10 days postinoculation with E. nieschulzi. Two or three coccidia-infected rats and two immune controls were killed at 2 and 5 days postchallenge with T. spiralis, and the worms in each third of the small intestine were recovered and counted. In every instance, rats that had concurrent coccidia infections harbored at least 4 times more T. spiralis than did immune, coccidia-free controls. Distribution of $T$. spiralis through the small bowel was not altered by infection with $E$. nieschulzi, despite the fact that the coccidian significantly suppressed worm rejection.

Information in the literature showed that rodent hosts infected with such nematodes as Nippostrongylus brasiliensis and Ancylostoma caninum, or with certain bacterial species, such as Salmonella typhimurium, were more resistant to primary infection with Trichinella spiralis than were their unparasitized counterparts (Brewer, 1955; Cox, 1952; Louch, 1962). Resistance to a secondary infection with T. spiralis in mice also was enhanced when the host was infected with A. caninum prior to challenge (Cox, 1952). Collectively, these findings are compatible with the premise that resistance to $T$. spiralis might be due to adverse changes in the parasite's environment (Larsh and Race, 1975). Such changes may be induced by inflammation caused by the priorestablished pathogens.

Inflammation, as reflected by mucosal peroxidase activity and granulocyte infiltration of

Received for publication 22 March 1977.

* Work supported by Research Grant AM-11361 from the NIAID, National Institutes of Health. Dr. Castro is the recipient of Research Career Development Award AI-00087.

$\dagger$ Department of Biology, The University of New Mexico, Albuquerque, New Mexico 87131.

* Department of Physiology, University of Texas Medical School, Houston, Texas 77025. the lamina propria, has been correlated positively with temporal and spatial distribution of $T$. spiralis in the small intestine of rats with primary trichinosis (Smith and Castro, 1975, 1977). Challenge infections in immunized rats were associated with a significant rise in peroxidase activity as early as day 2 postchallenge (Russell and Castro, 1977). In a similar but unrelated study we noted a decrease in mucosal peroxidase activity when rats were infected with an intracellular protozoan, Eimeria nieschulzi.

These observations stimulated the present investigation. We hypothesized that if acquired resistance to $T$. spiralis was directly related to the level of mucosal inflammation, E. nieschulzi, unlike other enteric parasites studied, might have a suppressive effect on the immune response. The following is a description of the initial experiment on which our hypothesis was based and of subsequent experiments designed specifically to test our hypothesis.

\section{MATERIALS AND METHODS \\ Experimental animals \\ The parasites used were a nematode, Trichinella spiralis (Owen 1835) Railliet 1896 and a coccidian Eimeria nieschulzi Dieben 1924. Larvae of $T$.}


spiralis were obtained for immunization and for challenge infections by pepsin digestion of infected mouse (CF-1 strain) skeletal muscle (Castro and Fairbairn, 1969a). The E. nieschulzi isolate was maintained in our laboratory by periodic serial passage in albino rats. Sporulated oocysts were stored in $3 \%(\mathrm{w} / \mathrm{v})$ aqueous potassium dichromate $\left(\mathrm{K}_{2} \mathrm{Cr}_{2} \mathrm{O}_{7}\right)$ at 4 to $6 \mathrm{C}$. The oocysts used in this study were 3 months old. Before being inoculated into rats, oocysts were washed 3 times in $0.85 \%$ $(\mathrm{w} / \mathrm{v})$ aqueous $\mathrm{NaCl}$ by centrifugation $(5 \mathrm{~min}$ at $115 \mathrm{~g})$.

\section{Peroxidase assay}

Six rats were infected with $10^{4}$ and six with $10^{6}$ sporulated E. nieschulzi oocysts and caged in pairs. Uninfected counterparts were caged similarly and used as controls. On days 2, 8, and 16 postinfection, respectively, 2 infected rats at each level of infection and uninfected controls were killed. Their small intestines were removed and divided linearly into thirds. Ten $\mathrm{cm}$ samples of intestine from the middle of each third were collected. Mucosal scrapings were prepared from each sample and peroxidase activity was measured according to Castro et al. (1974).

\section{Immunization}

Male Sprague-Dawley rats (Sprague Dawley, Madison, Wisconsin) weighing between 150 and $175 \mathrm{~g}$ were immunized by administration of 7.5 $\times 10^{3}$ freshly isolated $T$. spiralis larvae. They were caged in pairs and fed a stock diet of Lab Blox (Allied Mills, Inc., Chicago, Illinois) and water ad lib. Immunity was measured by the decrease in intensity and duration of the intestinal phase of a secondary infection as compared with a primary infection. An experiment was designed specifically to illustrate this point. Seven rats were challenged with $7.5 \times 10^{3} \mathrm{~T}$. spiralis larvae and killed at various times during the first week thereafter. Intestinal worms were recovered (Castro and Fairbairn, 1969b) and the number obtained compared to those recovered from 7 unimmunized rats. Twenty-eight rats which were inmunized 32 days previously were divided into 3 groups. Six rats in one group (A) and five in each of the other two $(B, C)$ were inoculated with $5 \times 10^{5}$ sporulated oocysts of E. nieschulzi. The four other rats/group were left uninoculated and were retained as immune controls. Inoculation was by administration of washed, sporulated oocysts by stomach tube after the rats had been lightly anesthetized with ether. Each of the 28 rats was challenged with $7.5 \times 10^{3} \mathrm{~T}$. spiralis larvae at 2 (Group A), 7 (Group B) or 10 (Group C) days postinoculation (PI) with E. nieschulzi.

Pans containing $3 \% \quad \mathrm{~K}_{2} \mathrm{Cr}_{2} \mathrm{O}_{7}$ were placed under each cage to collect feces from each pair of rats. The pans were large enough to cover the area under each hanging cage so that all material dropping through the mesh in the cage floors was collected. Feces from each pair of animals was examined twice before inoculation with $E$. nieschulzi to insure against extraneous nematode or coccidial infections. Feces were also collected for one 24-hr period during patency and/or for $24 \mathrm{hr}$ preceding the death of each rat and were examined to confirm the coccidial and noncoccidial status of the experimental and immunized controls, respectively. All fecal samples were processed for coverslip flotation by standard procedures (Duszynski, 1972). A fresh squash preparation (see Marquardt, 1966) was made of tissue from the midgut of the 3 rats in Group A, killed 2 postchallenge (PC) with $T$. spiralis ( $=4$ days PI w/ E. nieschulzi), to search for endogenous stages of the coccidian.

Two or $3^{\prime}$ coccidian-infected rats and 2 immune controls from each group were killed with ether at 2 and 5 days PC with T. spiralis. The small intestine was cut at its junction with the stomach and the cecum, perfused with $50 \mathrm{ml}$ of $37 \mathrm{C}$ saline solution and then cut into 3 equal lengths. Worms in the perfusate and in each linear segment were recovered alive according to published methods (Castro and Fairbairn, 1969b) and counted under a dissecting microscope.

\section{Statistical analysis}

Differences in peroxidase activity between infected and control rats were compared statistically using the $t$-test for paired data (Snedecor, 1956). Worm counts between groups were compared by the unpaired $t$-test (Snedecor, 1956). Percentages were transformed to arcsin values prior to analysis. $P$ values less than 0.05 were considered significant.

\section{RESULTS}

All rats used in this study were free of extraneous helminth and coccidial infections. Each rat inoculated with E. nieschulzi was confirmed either to harbor normal developmental stages of the parasite or to pass millions of unsporulated oocysts over a 24-hr period during patency. These findings indicated clearly that the coccidian developed normally through its entire life cycle and had no difficulty infecting rats, even those immunized against $T$. spiralis.

The ability of $E$. nieschulzi to suppress mucosal peroxidase activity is reflected by the results shown in Fig. 1. Although peroxidase activity rose at the beginning of infection and following the patent period, peroxidase levels were depressed at day 8 PI. Similar observations have been made consistently in our laboratory and will be reported in detail in a separate communication.

Differences in worm burden between $T$. spiralis-immune rats challenged on different 


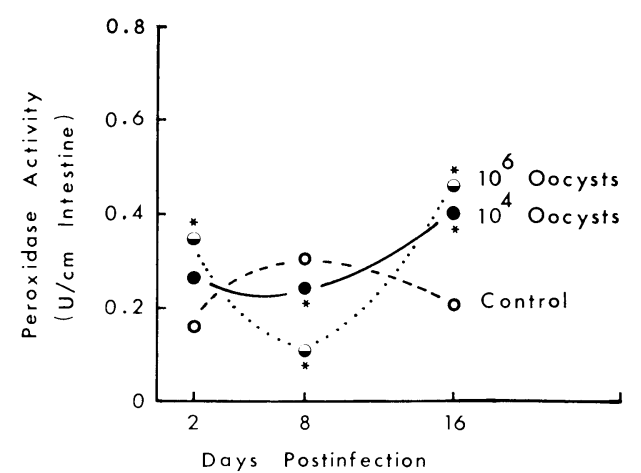

Figure 1. Peroxidase activity in mucosal homogenates from rats infected with $E$. nieschulzi and killed 2, 8, and 16 days postinfection. Each point is the mean of measurements made on samples from the proximal, middle, and distal gut from two rats inoculated with $10^{4}$ and $10^{6}$ oocysts, respectively, i.e., $N=6$ for each point designated for infected rats; $\mathrm{N}=12$ for control rats. Asterisk indicates significant difference $(P<0.05)$ as compared to control values. Significance was determined by the $t$-test for paired data.

days following infection with E. nieschulzi were not statistically significant; thus, these data were pooled. Results revealed that immunized rats infected with $E$. nieschulzi before challenge with $T$. spiralis retained significantly more worms than did immunized controls that were not infected with coccidia. These results can be compared in Fig. 2 with those obtained in the separate study designed to show the difference in intensity of the worm burden and in the duration of an infection in previously infected (immunized) rats as compared with immunologically naive rats.

Distribution of $T$. spiralis throughout the small intestine following challenge infection was not altered by the presence of $E$. nieschulzi, despite the fact that the coccidial infection significantly suppressed worm rejection. The percentage of worms was greatest in the proximal third of the intestine and least in the distal third. The percentage distribution did not differ from that in the immunized, control group (Fig. 3).

\section{DISCUSSION}

Immunity to $T$. spiralis is characterized by the fact that following a secondary encounter with the parasite, fewer worms establish in the intestine as compared to a primary infec- tion and the ensuing infection is of shorter duration. Our finding that a concurrent $E$. nieschulzi infection suppressed the immune response to $T$. spiralis as judged by these criteria, differed from the results of others (see introduction) who found concurrent enteric infections enhanced rejection of $T$. spiralis. Our results are compatible with observations of suppressed resistance to various infectious diseases in previously parasitized hosts (Woodruff, 1968). These findings indicate that the outcome of interactions between $T$. spiralis and other intestinal parasites is not consistently predictable.

The mechanism by which E. nieschulzi suppressed immunity to $T$. spiralis is not clear. One interpretation of our results is that stress produced by the coccidial infection lowered host resistance. This factor is known to impair immunity to helminths in a variety of hosts (Thorson, 1970). The importance of this factor in contributing to results in our study cannot be evaluated critically from data that we obtained.

Previous work emphasizing a proposed functional role for inflammation in rejection of intestinal worms offers an explanation of our results. If indeed inflammation is a requirement for worm expulsion the suppression of inflammation by $E$. nieschulzi may account for observed results. Although lowered mucosal peroxidase activity does not indicate that all phases of inflammation (Ebbert and Grant, 1974) are suppressed, it can be surmized that the normal influx of myeloid derived cells, hence, a major component of inflammation, into the lamina propria is retarded by the presence of the coccidia in the enterocytes. However, the fact that worm counts were higher in E. nieschulzi-infected rats even when T. spiralis infection was initiated as early as 2 days and as late as 10 days following coccidial infection indicates that factors other than reduced inflammation might be responsible for suppression of immunity in this particular hostparasite relationship.

The importance of inflammation in acquired resistance has been related to alterations produced in host tissues. Elimination of $T$. spiralis from its host purportedly is related to changes in the microenvironment that make survival impossible for the parasite. Recent findings 


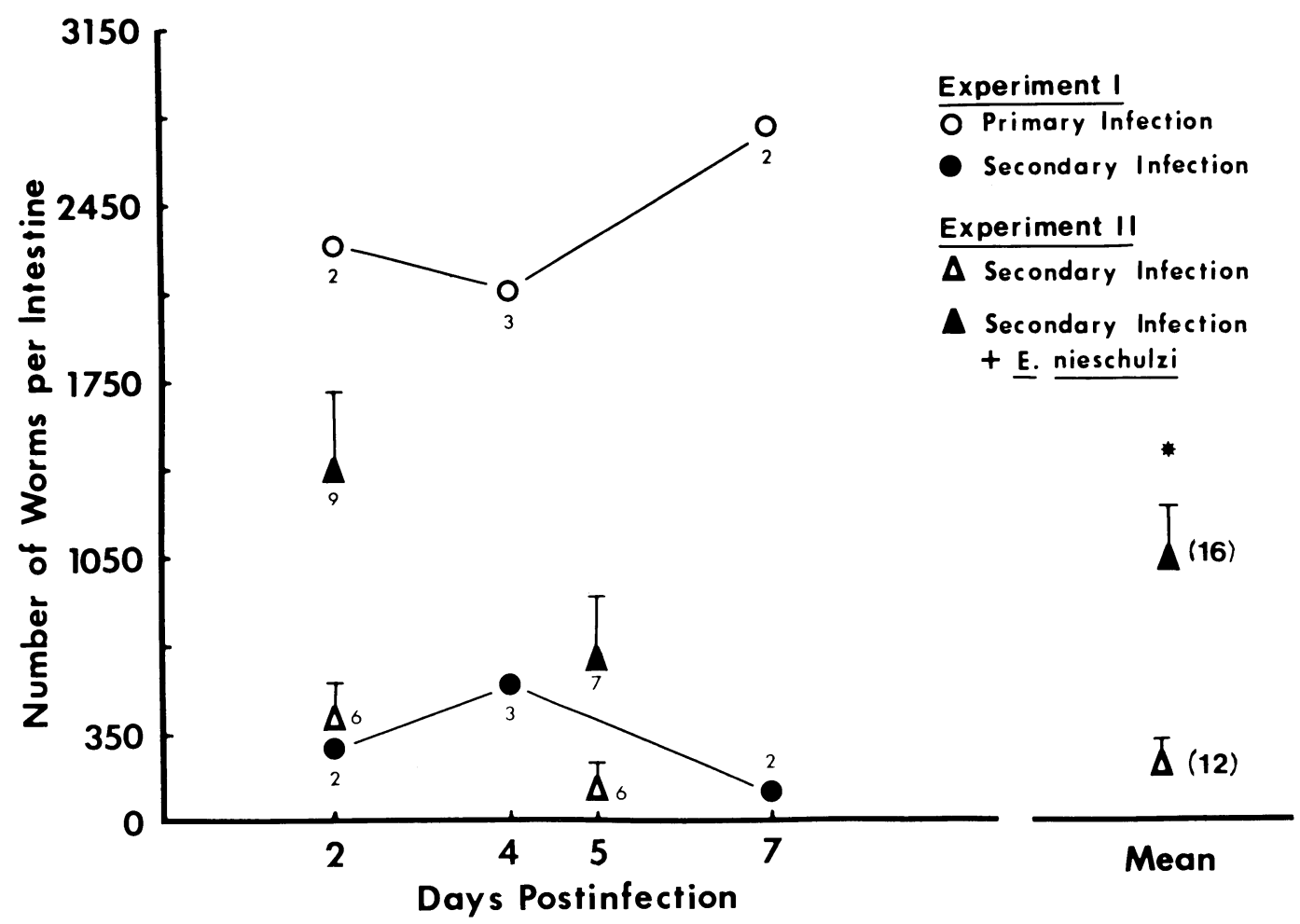

Figure 2. Experiment I: Intestinal stages of $T$. spiralis recovered from nonimmunized and immunized hosts after infection with $7.5 \times 10^{3}$ larvae. Experiment II. Worms recovered after infection with $7.5 \times 10^{3}$ larvae in immunized rats and immunized rats previously infected with $10^{5}$ oocysts of $E$. nieschulzi. Number in parenthesis $=\mathrm{N}$. Asterisk indicates significance $(P<0.05)$ between the mean number of worms recovered from immunized rats as compared to that of immunized rats infected with $E$. nieschulzi. The number associated with each point $=\mathrm{N}$.

regarding the life cycle of $T$. spiralis support the conclusion that the gut epithelium, rather than the lamina propria, is an important microhabitat for T. spiralis (Gardiner, 1976). If correct, this finding raises the possibility that acquired resistance may be related, in part, to reactions that prevent the worm from establishing in the epithelial layer or which are involved in expelling it from this specific habitat. It is axiomatic that such reactions involve the enterocytes and other cells which comprise the gut epithelium. As a corollary it can be surmised that factors that impair epithelial cell function alter acquired resistance to $T$. spiralis. Because of its intracellular nature, E. nieschulzi can be envisioned as an impairment to epithelial cell function. Evidence from ultrastructural (Sheppard, 1974) and histochemical (Pout, 1974) studies indicate that coccidia can alter enterocyte struc- ture and function. In our laboratory we have found that E. nieschulzi significantly depressed brush border disaccharidase levels and the absorptive capacity of the small bowel (unpublished data). If it is assumed that suppression of immunity to $T$. spiralis by E. nieschulzi is due to disruption of epithelial cell function, the effect on immunity should be more marked in the area of the intestine most heavily parasitized by the coccidia. Marquardt (1966) and Pellérdy (1974) suggested that E. nieschulzi has preference for enterocytes in the middle third of the small intestine. Liburd et al. (1973) found maximum florescence of labeled antibody in the crypts of the middle third of the small bowel day 10 PI to support these observations. Yet the impairment of immunity to $T$. spiralis by the coccidial infection was not restricted to the midgut. Although hosts in- 


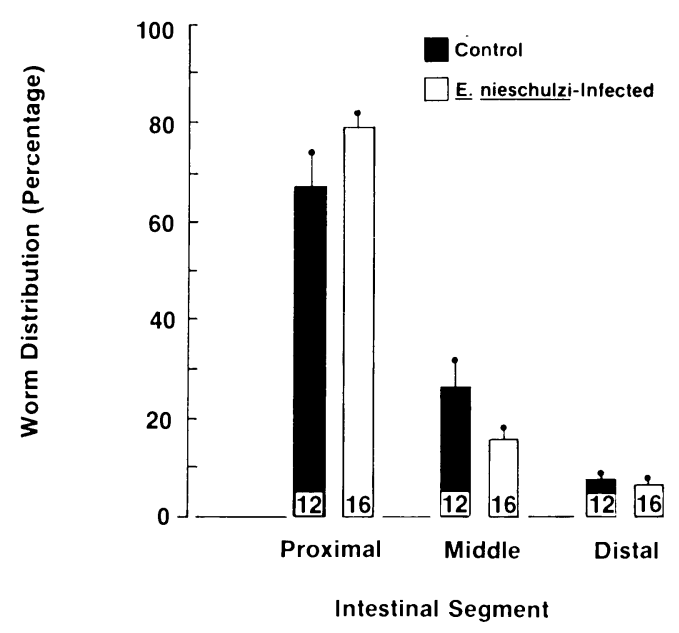

Figure 3. Distribution of T. spiralis within the intestine following challenge (secondary) infection in immunized rats (controls) and in immunized rats that were concurrently infected with $E$. nieschulzi at the time of challenge with $T$ spiralis. Rats were killed 2 and 5 days PC for recovery of intestinal worms. Due to no significant difference between the distribution patterns in rats killed at 2 or 5 days PC, data were pooled for statistical analysis. The number of rats in each group is designated by the number at the base of each bar.

fected with coccidia harbored significantly more worms following challenge, as compared to coccidia-free hosts, the distribution pattern was the same for both groups (Fig. $3)$. This finding suggests that suppression of immunity by coccidia is through a general rather than through a localized mechanism.

The work of Jones et al. (1976) offers an alternate explanation which is compatible with our results. These authors reported on suppression of a primary antibody response to sheep erythrocytes in mice infected with $T$. spiralis. Good and Miller (1976) reported a similar response in rats infected with Taenia crassiceps. A finding that is pertinent to our results was that the tapeworm infection suppressed the anamnestic response as well as the primary response to sheep erythrocytes. In both cases hosts responded intensely to homologous helminth antigens. Similar immunosuppression has been observed in humans infected with Plasmodium falciparum in response to inoculation with tetanus and Salmonella typhi vaccines (Greenwood, 1974). These findings are consistent with the concept of antigenic competition (Jones et al., 1976; Good and Miller, 1976), although the specific mechanism involved is not clear. Such phenomena may be important in altering the immune status of the host. It is possible that our observation of coccidial-suppressed immunity to $T$. spiralis is a correlate of the antigeninduced suppression of immune response induced by $T$. spiralis and $T$. crassiceps to sheep erythrocytes and by P. falciparum to Salmonella antigens.

\section{LITERATURE CITED}

Brewer, O. M. 1955. A study on the effects of Salmonella typhimurium on the acquired resistance of mice to Trichinella spiralis. J Elisha Mitchell Sci Soc 71: 170-171.

Castro, G. A., and D. Fairbairn. 1969a. Carbohydrates and lipids in Trichinella spirali. and their utilization in vitro. J Parasitol 55: $51-58$.

—_ AND 1969b. Effect of immune serum on glucose absorption and infectivity of Trichinella spiralis. J Parasitol 55: 59--66.

, S. A. Roy, ANd R. D. Stockstill. 1974. Trichinella spiralis: Peroxidase activity in isolated cells from the rat intestine. Exp Parasitol 36: 307-315.

Cox, H. W. 1952. The effect of concurrent infection with the dog hookworm, Ancylostoma caninum, on the natural and acquired resistance of mice to Trichinella spiralis. J Elisha Mitchell Sci Soc 68: 222-235.

DuszYNSKI, D. W. 1972. Host and parasite interactions during single and concurrent infections with Eimeria nieschulzi and $E$. separata in the rat. J Protozool 19: 82-88.

Ebbert, R. H., AND L. Grant. 1974. The experimental approach to the study of inflammation. In B. W. Zweifach, L. Grant, and R. T. McClusky (eds.), The Inflammation Process, Vol. 1, Academic Press, New York, p. 4-49.

Gardiner, C. W. 1976. Habitat and reproductive behavior of Trichinella spiralis. J Parasitol 62: 865-870.

Good, A. H., AND K. L. Miller. 1976. Depression of the immune response to sheep erythrocytes in mice infected with Taenia crassiceps larvae. Infect Immun 14: 449-456.

Greenwood, B. M. 1974. Immunosuppression in malaria and trypanosomiasis. In R. Porter and J. Knight (eds.), Parasites in the Immunized Host: Mechanisms of Survival, Ciba Foundation Symposium 25 (new series), Associated Scientific Publishers, New York, p. 137-146.

Jones, J. F., C. A. Crandall, and R. B. CranDALL. 1976. T-dependent suppression of the primary antibody response to sheep eryth- 
rocytes in mice infected with Trichinella spiralis. Cell Immunol 27: 102-110.

Larsh, J. E., JR., and G. J. Race. 1975. Allergic inflammation as a hypothesis for the expulsion of worms from tissues: A review. Exp Parasitol 37: 251-266.

Liburd, E. M., W. D. Armstrong, and J. L. MaнrT. 1973. Immunity to the protozoan parasite Eimeria nieschulzi in inbred CD-F rats. Cell Immunol 7: 444-452.

Louch, C. D. 1962. Increased resistance to Trichinella spiralis in the laboratory rat following infection with Nippostrongylus muris. J Parasitol 48: 24-26.

MarquardT, W. C. 1966. The living, endogenous stages of the rat coccidium, Eimeria nieschulzi. J Protozool 13: 509-514.

Pellérdy, L. P. 1974. Coccidia and Coccidiosis (2nd ed.), Verlag Paul Parey, Berlin, 959 p.

Pout, D. D. 1974. Coccidiosis of lambs. III. The reaction of the small intestinal mucosa to experimental infections with $E$. arlong $i$ "B" and E. crandalis. Br Vet J 130: 45-53.

Russell, D., AND G. A. CAstro. 1977. Intestinal

J. Parasitol., 64(1), 1978, p. 88

(i) American Society of Parasitologists 1978

\section{BOOK REVIEW . . .}

Marine Helminths and Human Health, by Harford Williams and Arlene Jones. Commonwealth Institute of Helminthology, Commonwealth Agricultural Bureau. CIH Miscellaneous Publication No. 3. 47 p.

Marine Helminths and Human Health attempts to synthesize the literature of marine zoonoses and those parasites which are potential human pathogens by providing a review of the literature and with illustrated life cycles. The grouping of the helminths involved by taxonomic groups makes the review useable. The reference list is comprehensive but not complete for all groups. However, it pathophysiology associated with rejection of an enteric parasite in immunized and nonimmunized hosts (abstract). Gastroenterology 72: 1123.

Sheppard, A. M. 1974. Ultrastructural pathology of coccidial infection. J Parasitol 60: 369 371.

Smith, J. W., and G. A. Castro. 1975. Peroxidase activity as a chemical index of inflammation in the small intestine. Gastroenterology 68: 99 .

, AND - 1977. Relation of peroxidase activity in gut mucosa to inflammation. Am J Physiol (in press).

Snedecor, G. W. 1956. Statistical Methods. Iowa State University Press, Ames, 534 p.

Thorson, R. E. 1970. Direct infection nematodes. In G. J. Jackson, R. Herman, and I. Singer (eds.), Immunity to Parasitic Animals, Vol. 2, Appleton-Century-Crofts, New York, p. 913-961.

WoodrufF, A. W. 1968. Helminths as vehicles and synergists of microbial infections. Trans R Soc Trop Med Hyg 62: 446-452.

provides key references and includes the earlier literature as well. The sections on Physiology, Behavior, Pathology and Immunology; Host-Parasite Relationships; Host-specificity are lacking in current concepts and reviews. However, despite the limitations of some sections, the taxonomic sections provide information which will be of value for teaching and of use to the layman for an understanding of the role marine helminths play in human health.

Betty June Myers 